\title{
Enhancing the Taxonomies Relating to Academic Integrity and Misconduct
}

\author{
Loreta Tauginiené $^{1}$ (D) Inga Gaižauskaitè ${ }^{2} \cdot$ Salim Razi $^{3} \cdot$ Irene Glendinning ${ }^{4}$. \\ Shivadas Sivasubramaniam ${ }^{5} \cdot$ Franca Marino $^{6} \cdot$ Marco Cosentino $^{6}$. \\ Alla Anohina-Naumeca ${ }^{7}$. Julius Kravjar ${ }^{8}$
}

Published online: 8 October 2019

(C) The Author(s) 2019

\begin{abstract}
A clear understanding of terminology is crucial in any academic field. When it is clear that complex interdisciplinary concepts are interpreted differently depending on the academic field, geographical setting or cultural values, it is time to take action. Given this, the Glossary for Academic Integrity, newly developed by the European Network for Academic Integrity project, served as the basis for compiling a comprehensive taxonomy of terms related to academic integrity. Following a rigorous coding exercise, the taxonomy was partitioned into three constituent components - Integrity, Misconduct and Neutral terms. A review of relevant literature sources is included, and the strengths and weaknesses of existing taxonomies are discussed in relation to this new offering. During the creation of these artefacts the authors identified and resolved many differences between their individual interpretative understandings of concepts/terms and the viewpoints of others. It is anticipated that the freely-available glossary and taxonomy will be explored and valued by researchers, teachers, students and the general public alike.
\end{abstract}

Keywords Academic integrity · Academic misconduct - Taxonomy· Research integrity Research misconduct · Qualitative content analysis · Concept analysis

\section{Introduction}

Academic integrity encompasses principles, norms and regulatory frameworks instrumental for driving appropriate conduct in education and research. The term 'academic integrity' has been defined as "compliance with ethical and professional principles, standards, practices and consistent system of values, that serves as guidance for making decisions and taking actions in education, research and scholarship" (Tauginiene et al. 2018a, p. 7-8). In fact, very few studies have been published so far on the definition of integrity and misconduct across

Loreta Tauginienè

loreta.tauginiene@hanken.fi

Extended author information available on the last page of the article 
different disciplines (e.g. Bretag (2016) and Macfarlane et al. (2014) discussed the definition of integrity and misconduct in different geographical contexts) and most of the earlier studies took place outside the academic community (e.g. Komić et al. 2015).

There are several reasons why it is important to develop and exchange terminology in the field of academic integrity. One reason is to shape a homogeneous understanding of academic integrity and misconduct. This would help academics and other stakeholders within higher education to make more informed decisions about maintaining normative standards against unethical or questionable behavior in academia, either for deterring or sanctioning misconduct (e.g. Adam et al. 2017; East 2010). The second reason relates to how we perceive (un)ethical behavior. We refer here to a common perception that academic practices vary in different fields of science. However, we believe that there should be a consistent understanding across academia concerning academic integrity and misconduct. In other words, there should not be any differences in interpreting what is academic integrity or misconduct in different academic fields. It would not make sense for ethical norms in academia to differ according to whom or where they are applied and whether it involves students, teachers, researchers, or administrative staff (Tauginienè 2016). Ambiguity in meaning should not arise in country specific interpretations.

The research of Becher (1989), Caudron (1994) and Garrett and Davies (2010) suggest that different sub-cultures exist within academia (e.g. in departments, institutes, researcher teams). It is likely that different perceptions on (un)ethical behavior may derive from such settings. Although there are many field-specific academic networks that promote academic integrity (e.g. publicizing statements, codes of ethics), and diverse academic viewpoints about ethical conduct, it seems appropriate to propose a more unified approach to such important concepts.

A consistent understanding and the use of agreed terms allows the prospect of a shared set of values. It also allows a possibility of developing internationally acceptable common solutions relating to teaching methods, content and preventative strategies for academic misconduct. Reaching agreement on these fundamental concepts would in turn lead to alliances between various fields of science. However, to achieve this, variations in the conceptualization and use of key terms need to be discussed and agreed. Consequently, we shed light here on concepts related to academic integrity and misconduct that derive from agreement, based on community norms. Also, as research in this field is advancing rapidly, new terms are constantly emerging and being widely adopted or used in scientific literature and other contexts (e.g. reports, lawsuits). Therefore, it is essential to address the need for a compendium of these terms with their meanings.

Such concepts have "a life cycle determined by cognitive and societal dynamics" (Picht 2013 , p. 11). Therefore, it is natural that various factors would affect the development of a concept. However, the desired outcome of an individual's ethical behavior is complicated, because it depends on imposed habits/rituals which may result in cultural differences based on the interpretation of terms.

To some extent, the interpretation of terms related to academic integrity and misconduct is culture-bound. In this respect, revisiting our understanding of the definition of culture would be useful before dealing with these cultural differences. Liddicoat et al. (2003) define culture as "a complex system of concepts, attitudes, values, beliefs, conventions, behaviors, practices, rituals and lifestyles of the people who make up a cultural group, as well as the artefacts they produce and the institutions they create" (p. 45). This implies that universities as institutions may be subject to different practices that are appropriate to the traditions and lifestyles of their communities. Hence there is a need for shaping homogeneous terminology that stems not only 
from science and research, but also from society (Szapuová and Nuhlíček 2015). It is also evident that academic research is no longer a national affair since it is very much internationally orientated. The mechanisms that lead to fraud, deception, or looking the other way, are universal (Plašienková 2016). Within this scope, institutional academic integrity policies are impacted by society's cultural values.

Furthermore, the need to address issues of terminology related to academic integrity and misconduct relies on the specificity of scientific fields, such as biomedical research, where the importance of specific behaviors may be very different. For example, adherence to ethical principles in clinical research implies that research is conducted according to the Declaration of Helsinki (1964). Also, authorship practices in scholarly pieces may differ greatly across disciplines. Indeed, the most acknowledged guidelines in medicine and biology are those from the International Committee of Medical Journal Editors (ICMJE, http://www.icmje.org/), which require named authors to make substantial contributions to design and execution of the work as well as involvement in writing the manuscript. In addition, in biomedicine the order of authors has specific significance. By contrast, other scientific areas (e.g. physics) may include in the list of authors people unfamiliar with the specific study and often put the authors in alphabetical order.

Authorship in academia is however fundamental for both accountability towards stakeholders and society as well as for individual reputation and career progression of scholars; therefore, reflecting on the meaning of authorship across academic disciplines is of paramount importance (Tauginienè et al. 2018b). Given such examples, the question remains open whether existing terminology compiled by reputable organizations is genuinely and consistently put into practice.

Other reasons to develop and exchange interpretations of terminology relate to the fact that definitions can be too narrow and ambiguous (Gaižauskaite and Tauginiene 2017; McClung and Schneider 2015; Picht 2013), or broad-ranging and contested (Bretag and Mahmud 2009; Burrus et al. 2007; Curran 1976), which fail to reflect current trends and threats. Thus, it is difficult to deal with research misconduct institutionally or legally if there is no common agreement on the exact meaning of terms such as integrity (Horbach and Halffman 2017; Jordan 2013) or plagiarism (Upleja 2012). For example, the Latvian academic terminology database AkadTerm does not include terms such as "academic integrity", "academic honesty", and "academic misconduct". Another example relates to international research collaboration where different institutions may interpret the same behavior in different ways (Resnik et al. 2015a, b). This affects various stakeholders such as authors, editors, reviewers and readers (Wells and Farthing 2008 as cited in Regmi 2011). Students sometimes fail to understand academic standards due to ignorance and misunderstanding of various terms (East 2006; Roberts 2008 as cited in Ho 2015), which impedes efforts to combat misconduct (Salwén 2015).

Overcoming this lack of understanding necessitates sustained effort and justification to achieve societal acceptance (Picht 2013), i.e. harmonizing academic integrity terminology in order to avoid, or at least minimize, further pitfalls. Evidence from prior studies indicates that having a set of clear definitions and requiring that students read these will reduce the number of violations (Burrus et al. 2007). Therefore, studies on academic integrity should endeavor to unify the meaning of concepts related to both academic integrity and academic misconduct as much as possible (East 2006; Fielden and Joyce 2008; Horbach and Halffman 2017; Jordan 2013; Steneck 2006). Despite the contributions from previous studies, a systematic focus on the revision and clarification of an extensive pool of terms relating to academic integrity has not yet been conducted. 
For all these reasons we aim here to provide a taxonomy of honest and dishonest behaviors that links to academic integrity and academic misconduct. In fact, by creating this classification and glossary, we aim to provide content-specific explanations that will facilitate the use and sharing of these terms by students, scholars and the general public.

This paper begins with a review of the literature related to academically honest and dishonest behavior. We then provide an illustrative taxonomy organized into three distinct constituents and ends with a discussion and conclusions.

\section{Literature Review}

Academic integrity has been a focal point for research as well as practice in recent years. A number of high-profile dishonest practices have been identified (e.g. Weber-Wulff 2014, 2016), resulting in a negative impact on scholars and public figures. At the same time, academic integrity is probably one of the least-explored issues at higher education institutions in developing countries (Heitman and Litewka 2011). Earlier studies have shown that students from countries with minimally established academic integrity policy often lack an understanding of academic integrity and therefore are at higher risk of committing plagiarism (Bamford and Sergiou 2005; Park 2003).

Although research in this field has increased, there remains a paucity of literature that consistently and comprehensively examines academically honest and dishonest behavior of both students and academics. Several studies are devoted to categorizing types of misbehavior in research and higher education. Resnik's work identified between thirteen (Resnik et al. 2015a) and seventeen (Resnik et al. 2015b) types of misbehavior in research, while McClung and Schneider (2015) listed eighteen categories of academic misbehavior. Al-Marzouki et al. (2005 as cited in Regmi 2011) reported 60 items related to research misconduct. Kumar (2008) revised the types of scientific misconduct in biomedical research, identifying several behaviors besides fabrication, falsification and plagiarism, which are those usually acknowledged by the scientific community. These include malpractice common to other areas, such as omission of citations of sources as well as practices that are more or less exclusive to biomedical sciences, such as unethical animal or human experimentation, photo-manipulation, data augmentation and others (see Table 1). Meanwhile, Hall and Martin (2019) developed a taxonomy for business schools organized according to the stakeholders affected and the severity of the misconduct. They grouped behaviors related to research misconduct as well as inappropriate and questionable conduct. The importance of concepts in academic integrity has served as another criterion for listing terms related to academic integrity (Jordan 2013). The taxonomies included in these four studies are detailed in Table 1.

Returning to the subject of cultural differences, academic integrity may be associated with community values. To demonstrate this, we provide an example from Turkey, where it is a not an uncommon practice in recent times to deal with 'academic integrity' under the umbrella term 'values education', especially in the case of providing awareness of ethical issues (e.g. Cihan 2014). Values courses were added to the curriculum at all levels (primary, secondary, high school) by the Ministry of Education in 2011, the roots of which date back to a project supported by UNESCO. By dealing with issues beyond the scope of academic integrity, values education mainly aims at developing personal integrity through extra-curricular activities.

Academics are expected to adapt to evolving requirements on a regular basis, such as new technologies and institutional pressures (de Weert 2001; Geppert and Hollinshead 2017), and, 


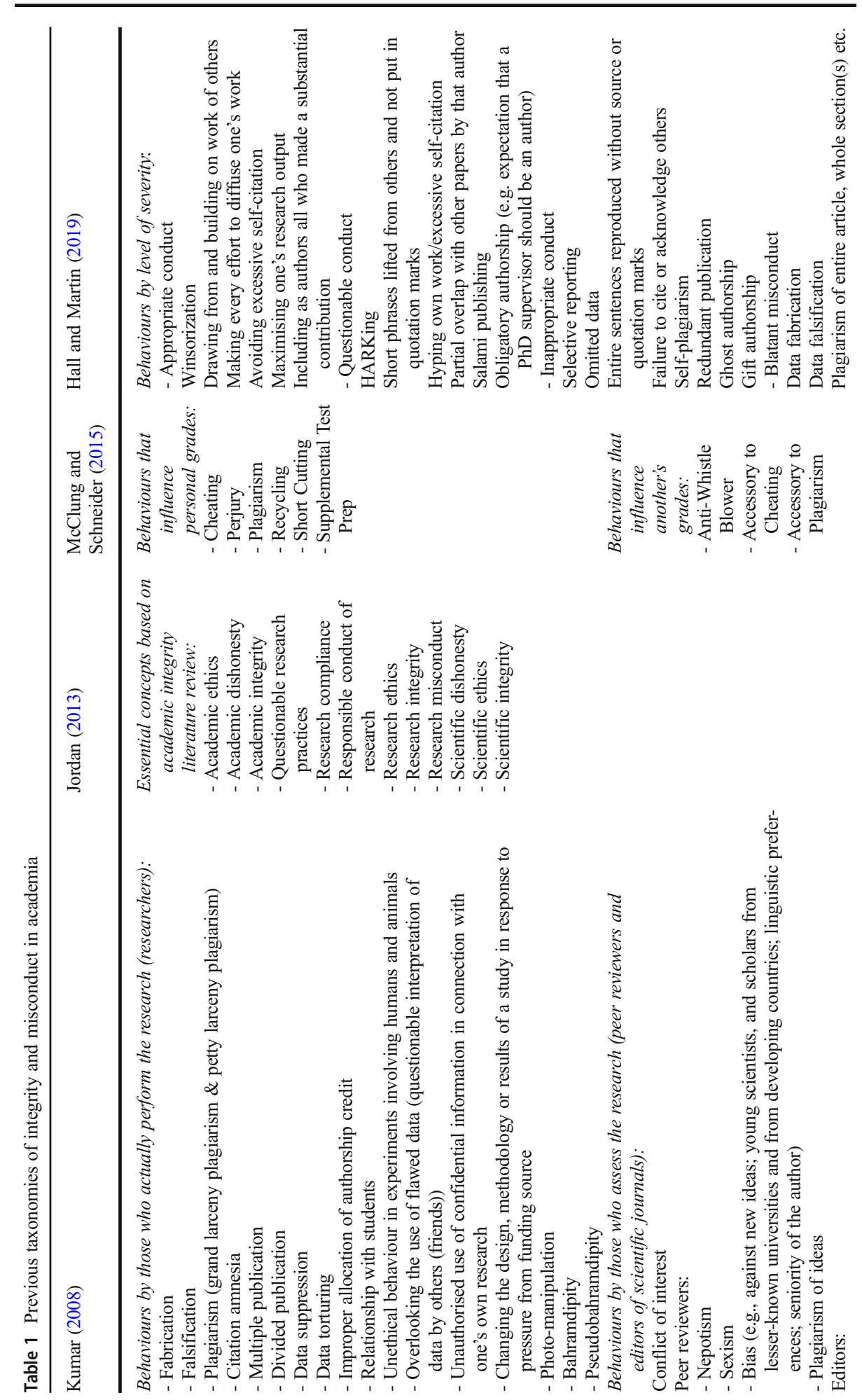




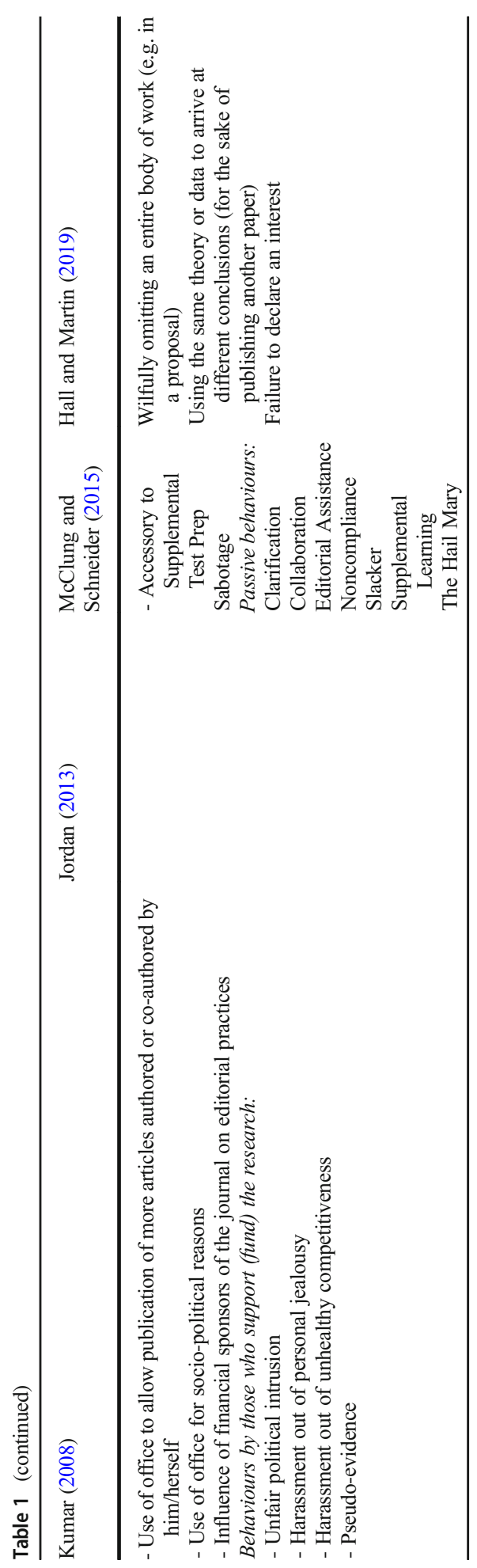


naturally, to modify their behavior. Therefore, it is possible that research misconduct has become more diversified and thus more confusing in the process (Bohannon 2013; Maddox 2008 as cited in Ho 2015; Martin 2013). As McCabe et al. (1999) and, more recently, Salwén (2015) pointed out, universities use different misconduct-related definitions, resulting in different understandings of what misconduct is. Hence, the same type of misconduct is not always treated with the same response in all universities.

In pursuance of the quest to provide an inclusive taxonomy of academically honest and dishonest behavior, we will revisit two taxonomies; one for academically dishonest behaviors developed by McClung and Schneider (2015) and the other concerning academic integrity concepts proposed by Jordan (2013). We will then align them with our own taxonomy. We limited alignment of the developed taxonomy to these two more general taxonomies because other taxonomies, such as Kumar's (2008) classification and Hall's and Martin's (2019) taxonomy, derive from field-specific research.

\section{Methodological Approach}

\section{Data Collection}

For the purpose of analysis, we selected 212 terms included in the glossary for academic integrity (Tauginienè et al., 2018a) that had already been developed by the authors of this paper. This glossary was developed by an international interdisciplinary team in an attempt to reach a shared understanding of concepts related to academic integrity and misconduct in academia.

This glossary was created by applying a robust approach from the outset of the development, which helped to ensure the validity and relevance of the chosen terms and their definitions. The following brief description of the stages of the glossary development evidences the rigorous approach adopted by the team (authors of this paper, the glossary and taxonomy). Using the World Café approach for experts' knowledge sharing, we identified potential sources where relevant terms and their definitions could be found. During this process we collated information from a pool of credible sources (see Tauginienè et al., 2018a):

- previous and current international and national sister projects (at international level such as Printeger, Satori, Respect, etc.; at national level such as Refairence in Germany, MTEtika and AcadAu in Lithuania);

- international organizations with expertise in or consideration of ethics (such as the European Science Foundation, Committee on Publication Ethics, International Center for Academic Integrity, etc.);

- networks (such as the European Network of Research Integrity Offices, PanEuropean Platform on Ethics, Transparency and Integrity in Education, European Network of Research Ethics and Research Integrity, etc.);

- internationally-recognized academic publishers (such as Springer, Elsevier, Routledge, etc.);

- partner country national reports (published by research councils or other public bodies);

- legislation and other relevant sources (for example, suggested research papers by project partners where academic integrity-related terms were analyzed, and the websites of a few universities were consulted). 
In total, over 60 core sources were selected, some encompassing more than one document. Next, all documents available online were reviewed, looking for terms related to any aspect of ethics or academic integrity in academia, scholarship, teaching or research. Initially, all terms that could be identified were collected. These included terms with or without a definition, with the same or nearly the same meaning. Based on the documents reviewed, 440 individual terms were collected. In addition, a further 30 terms were suggested based on the expertise of project partners. Collected terms were structured in the following way - term, definition, source with full description, and online link (Tauginienè et al. 2018a).

\section{Data Analysis}

A refinement process for each term and its definition was initiated. The final glossary comprised a set of 212 entries with terms relevant to academic integrity, decided via face-toface and virtual working group meetings. Different strategies were used with the terms that were removed. For instance, over 260 terms were removed from the glossary due to their ambiguity and nuance related to connotation. Some terms were aligned either as synonyms of retained terms (over 30) or used for the development of general guidelines (over 20) (Tauginiene et al. 2018a). The final version of the glossary was agreed by partners from different countries (Germany, Italy, Latvia, Lithuania, Portugal, Slovakia, Slovenia, UK), and from various institutions and scientific fields (such as history, sociology, medicine \& allied sciences, computer science, business, and mathematics).

We combined the methodological approaches of concept analysis and content analysis. Though the glossary principally serves a practical purpose, the process of its development was in line with the principles of concept analysis (Foley and Davis 2017; Nuopponen 2010a, b, 2011). The glossary itself aimed at bringing more clarity and common understanding to the use of academic integrity-related concepts, deriving a substantial set of reliable, widely-used and academic integrity-focused terms. Refinement of each term by an international and interdisciplinary team led to the final list of terms that well reflects the current conceptual field of academic integrity. Therefore, we further aimed to conduct a thorough analysis of the thematic domains of the terms included in the glossary and the relationships between them. For that purpose, we applied qualitative approach principles to the content analysis (Krippendorff 2013).

We developed the coding system using a thematic-coding perspective. For each term in the glossary, we assigned a code that connotes the essential conceptual meaning of its definition. Due to the word limit constraints of this journal, we are unable to provide comprehensive definitions of each term. We strongly recommend that readers consult the freely available ENAI Glossary for Academic Integrity (Tauginiene et al. 2018a) to understand these definitions.

The initial proposal for constructing the coding system was based on previous attempts to classify academic integrity and misconduct-related concepts. Based on interviews with experts, OECD (Best Practices 2007) provided the following categories of misconduct: research misconduct; data-related misconduct; personal misconduct; research practice misconduct; publication-related misconduct; financial misconduct and miscellaneous misconduct. Horbach and Halffman (2017) proposed the empirically-derived themes of: authorship; education; finance; institution; integrity; misconduct; policy; academic promotion; repression; science; society, and virtue. Steneck (2006) constructed a continuum of research behaviors ranging from the ideal to the worst in three categories: ideal behavior as responsible research practice 
(RPR); worst behavior as exemplified by fabrication, falsification, and plagiarism (FFP), and questionable research practices (QRP) in between. In the same vein, Hall and Martin (2019) suggested three groups of behaviors (see Table 1).

However, all these examples and the taxonomies discussed in the Literature review section are either too broad (general) or restricted to a certain thematic domain of integrity (misconduct). Therefore, we had no alternative but to develop an expanded coding system that allowed us to encompass all terms in the glossary.

We applied triangulation of the researchers' expertise and views to validate the initial coding system. Three of the co-authors of this article volunteered to independently code each of the glossary terms; subsequent discussions then led to a consensus on the outcomes. Afterwards, a final coding system was developed, and this was applied to the analysis of glossary terms.

Three individual coders (i.e. the three co-authors) separately assigned primary codes to each term in the glossary. Furthermore, we checked for compatibility of the primary codes. These fell into three groups. In the first round, we marked the codes that were (1) in full agreement (i.e. all three coders assigned exactly the same code for a term, or the codes assigned were only different in the sense of being synonyms but connoted the same essential meaning, e.g. "breach" and "abuse"); (2) codes that were in partial agreement (i.e. two coders assigned the same code whereas one of them proposed a different code), and (3) codes for which there was no agreement between coders (i.e. all three coders assigned a different code to the term). Out of 212 terms, we fully agreed on the codes for 20 terms (11.3\%), partially agreed on the codes of 97 terms (45.8\%) and disagreed on the codes of 91 terms (42.9\%). It is worth mentioning that no other coefficient of the reliability of content analysis data was applied. This decision was based on the apparent coefficient's limitations, such as number of coders, and sample size. For example, Cohen's kappa shows the relationship between two coders while our data were coded by three coders. Likewise, Krippendorff's alpha is applied to large sample sizes while our dataset is small (Krippendorff and Bock 2009).

This resulted in the second round of coding, where we looked for common agreement on primary codes between all three coders. After discussing the code of each term, coders did not assign any code to 8 terms because these terms were either used as codes themselves (e.g. principle), were too broad (e.g. culture of academic integrity) or too general (e.g. academic (adjective)). Coders reached full inter-coder agreement on the remaining 200 terms.

We further grouped all coded terms into three categories: integrity (terms whose definitions connote assurance and promotion of integrity as well as serving this purpose); neutral (terms with definitions relating to the field of academic integrity; however, they do not bear any particular connotation, either integrity or misconduct); and misconduct (terms whose definitions connote a variety of breaches of integrity). While making decisions regarding the category, coders referred to the definition provided in the glossary. It should be noted that we assigned some terms to two categories. For example, 'neutral' to those terms that are polysemic or have definitions with different connotations (e.g. the term 'crib-notes' may be a tool used for memorizing information (neutral connotation) or as a cheating tool (misconduct connotation)). We visualized these cases using a dashed line.

Where applicable, we grouped codes into mid-level sub-categories based on the locus of occurrence (e.g. such terms as "authorship abuse" and "coercion authorship" under the code of behavior were sub-categorized into 'authorship'). Compiled codes, sub-categories and categories denote our expert-knowledge and literature-based judgements as to what a term relates to. Based on these links, we finally produced concept maps using graphics program Edraw MindMaster that reveal visually the field of academic integrity as integral parts of the taxonomy (see Figs. 1-3). 


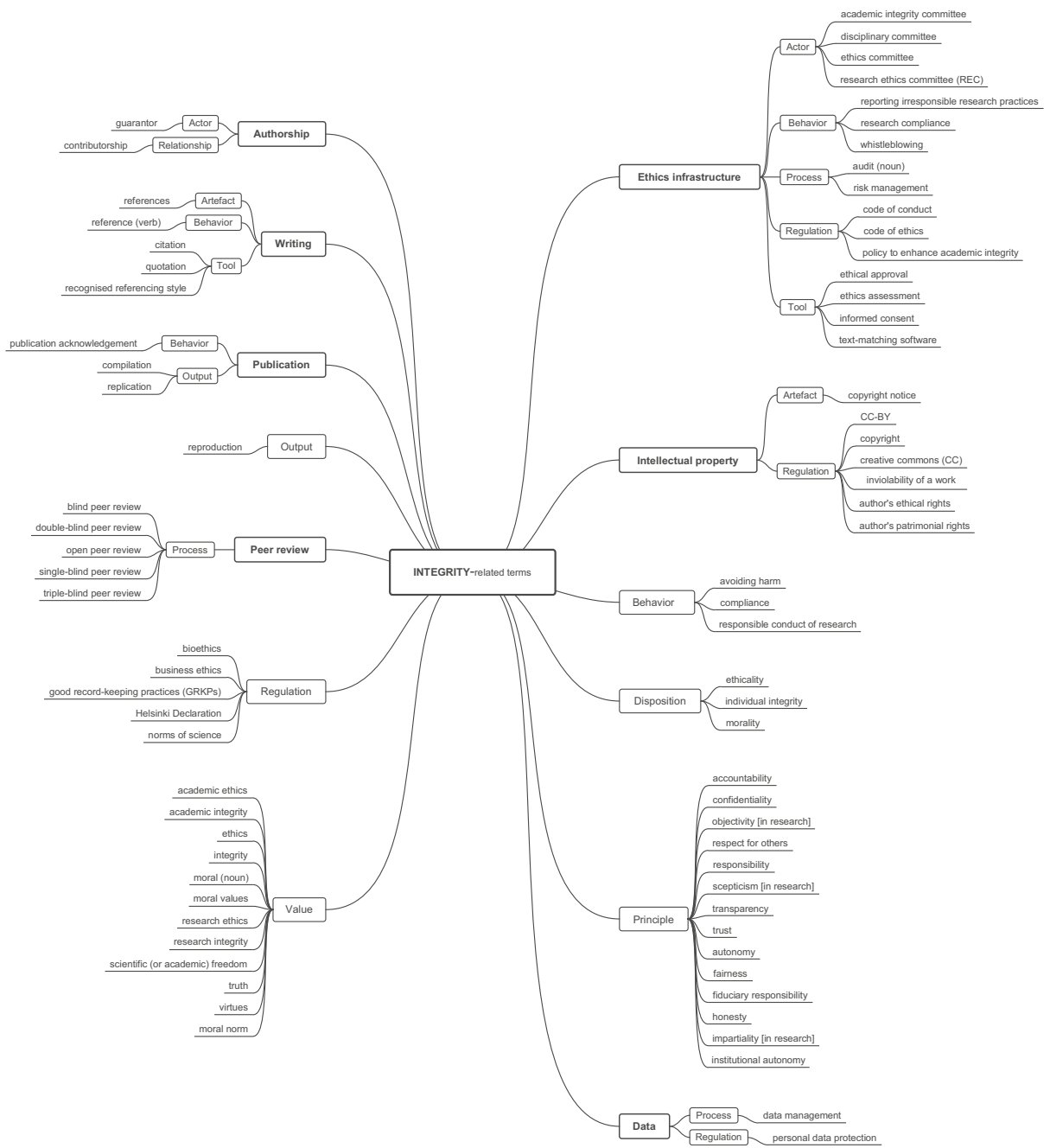

Fig. 1 Terms related to integrity

\section{Findings}

The rigorous ENAI glossary development procedure revealed a spectrum of terms related to integrity in academia to date (see Figs. 1-3). This finding elevates academic integrity as a specific scientific field and practice. Hence, while generating the taxonomy of academically honest and dishonest behaviors that link to academic integrity and misconduct, three separate constituents emerged - Integrity, Misconduct and Neutral. The Neutral constituent covers integrity-related terms that are distinguished by different connotations; in some contexts, some of the Neutral terms can be considered as malpractice or integrity.

The Integrity constituent identifies a wide variety of terms related to virtues (37.2\%) and ethics infrastructure (20.5\%) (see Fig. 1), while, behavior-related terms are prevalent $(70.3 \%)$ in the Misconduct constituent (see Fig. 3), particularly linked to plagiarism and authorship. The Neutral constituent is the most diversified in terms of sub-categories (see Fig. 2). 


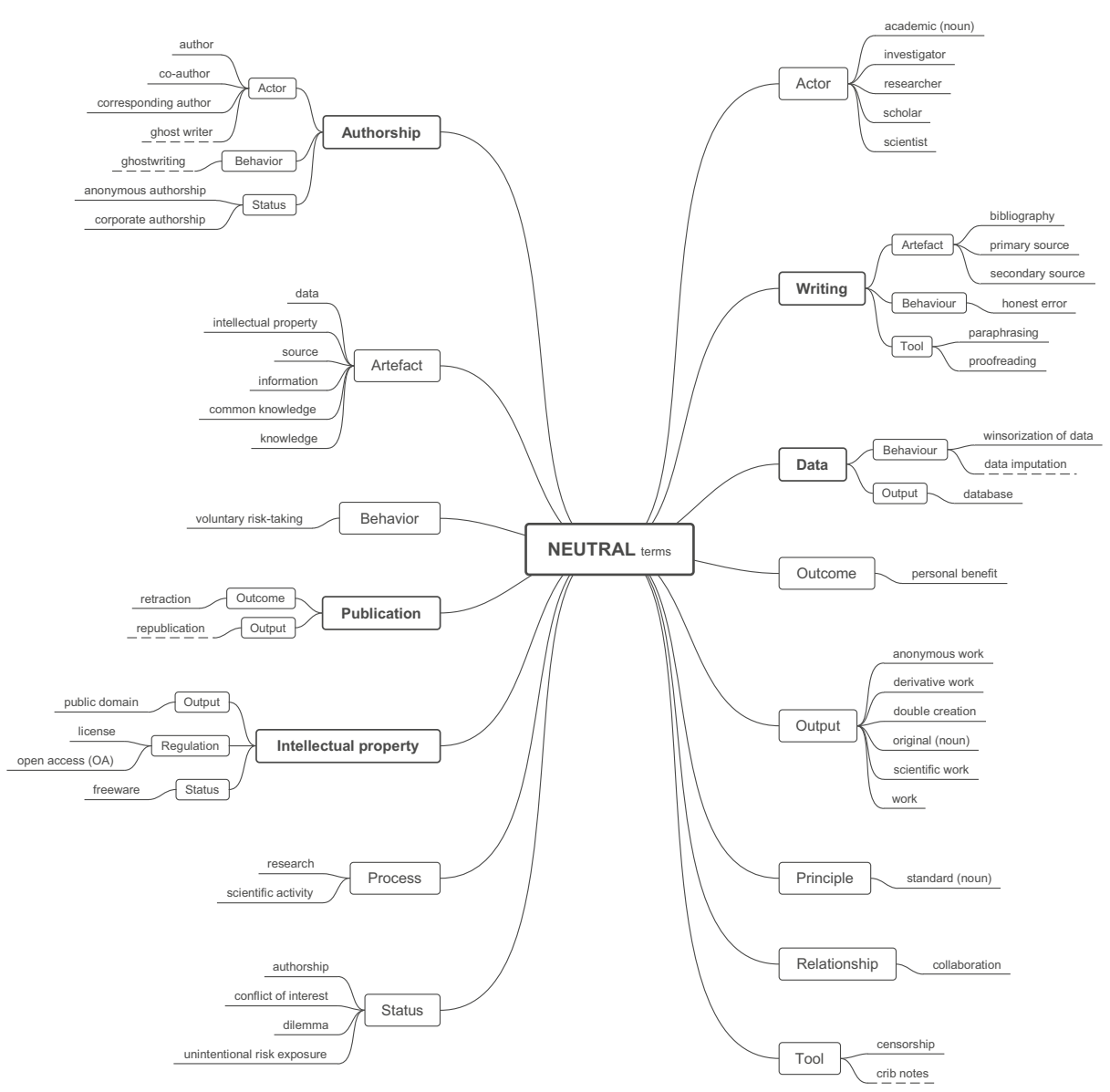

Fig. 2 Neutral terms

\section{Discussion}

The term "academic integrity" has become a focal point in higher education organizations around the world. Whilst many institutions are focusing on teaching and establishing acceptable behaviors within this context, the interpretation and conceptual understanding of terms linked to integrity can vary depending on the field of study, from country to country or even institution-to-institution (CSE White Paper 2012). Therefore, a glossary of terms for the study of academic integrity developed through a well-defined conceptual taxonomy would be an important contribution to the field. Most crucially, the glossary should focus on providing examples of the empirical functions of the terms it defines.

The establishment of ENAI (as an association) in 2017 provided an opportunity for European academics working in different disciplines to come together to address this vacuum. The multi-disciplinary input impelled us to produce this glossary with meanings and examples to suit a wide audience of people either involved or interested in integrity-related issues. However, this multidisciplinary approach did generate some issues. Bringing together scholars from various fields and then expecting them to avoid misunderstandings in their oral and 


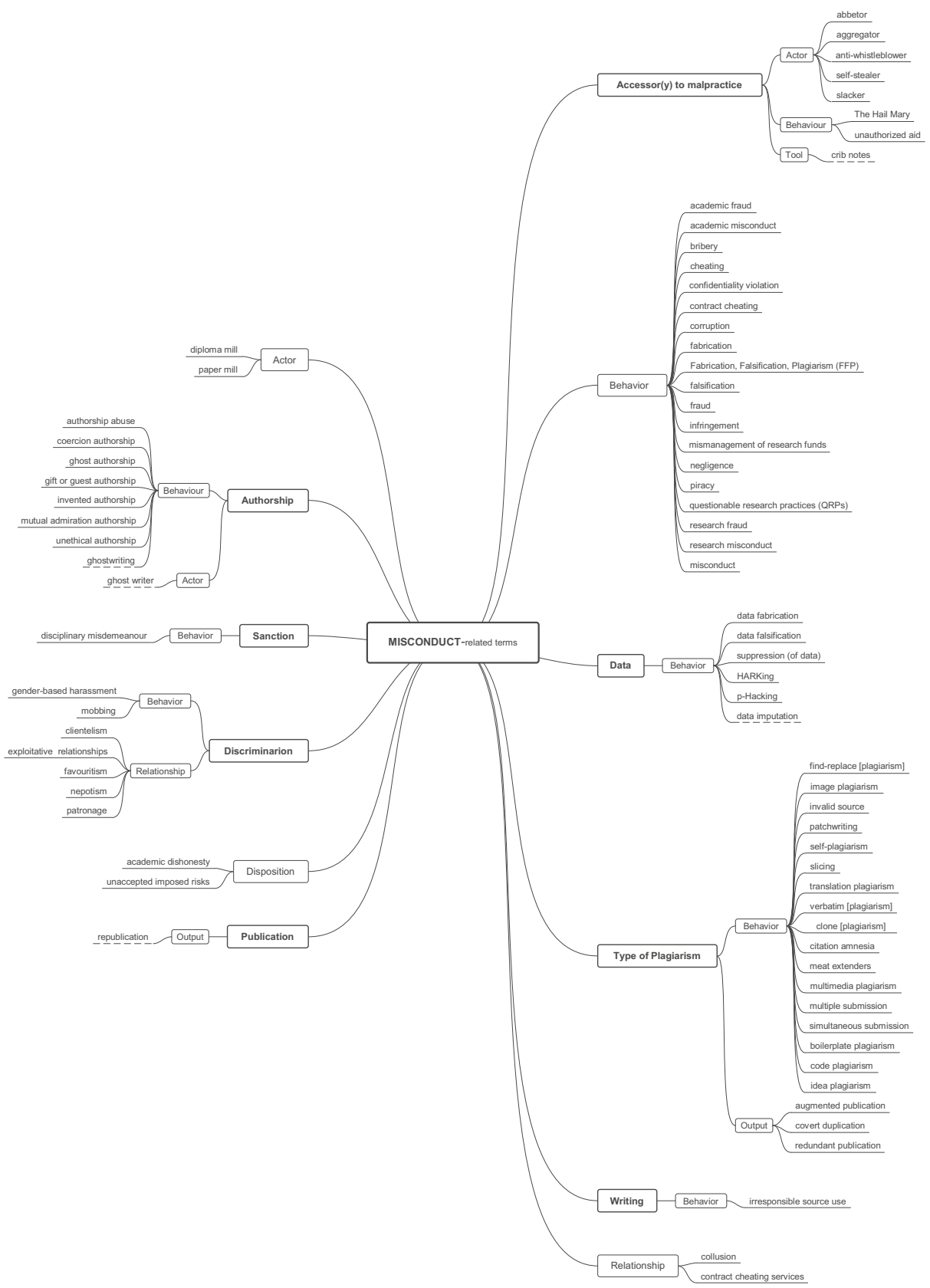

Fig. 3 Terms related to misconduct

written communications would be naïve. This is because these scholars rely on different sets of knowledge and experience; thus, their comprehension of the same text, either in written or spoken form, may vary. Despite this, we achieved consensus by creating an up-to-date glossary addressing the terms related to both integrity and misconduct (positive and negative connotations, respectively). 
To the best of the authors' knowledge, only two previous studies (Jordan 2013; McClung and Schneider 2015) have attempted to highlight the importance of rational conceptualization in the form of a clearly-defined glossary. Jordan (2013) argued for minimizing "conceptual stretching" and pointed out that the term "ethics" itself may have different connotations in different contexts. She argued that trying to provide a glossary including meaning (and usage) of terms outside their contexts might result in confusion. In contrast, in a world where integrity has recently gained importance (and/or become legitimized), we feel that simplified definitions may reduce the wider applicability/receptivity of these terms. For instance, in the example glossary given in Jordan's study (box 2 in Jordan 2013), the definitions for academic ethics and research ethics had only minor differentiations. Whilst the former was linked to individuals (or institutions) "in education, research or scholarship settings", the latter were linked to academics/academia "where systematic, generalizable knowledge is produced or disseminated". However, in practice, scientific research integrity encompasses much wider connotations that involve research conduct, ethics, methodological clarity, and so on. Therefore, we feel that this way of generalizing the definition would not provide conceptual clarity. However, we accept the fact that it is difficult to give a definition that would suit all contexts and situations. In the taxonomy presented here, we have developed generalized definitions adjusted to suit the fields where they are extensively used and/or adhered to.

McClung and Schneider (2015) created a taxonomy of dishonest behaviors based on searches of literature databases. They believed that by identifying and classifying dishonest behaviors, their research would assist students in higher education to become more professional. Unlike Jordan (2013), these authors tried to give examples of dishonest behaviors in addition to their definitions. Yet since this was a meta-analysis, their definitions might have been influenced by the interpretations given in the original 17 articles that were selected for this study. Further, they claimed that these definitions of academic misconduct would assist in developing institutional policies. Although we accept that their findings may have provided clarification about different types of academic misconduct, the study only focused on "misconduct" (as opposed to integrity); therefore, the applicability of this compendium to institutional policies is limited. Also, we argue that it would be more logical to provide a taxonomy based on a lexicon relating to good academic practice, or to take a more holistic approach by addressing all relevant terms (positive and negative) relating to "integrity" with their meaning and examples to address, or be applicable to, a wide range of different disciplines.

Studies in the relevant literature provide examples of problems in comprehension between different academic fields (see Carrell 1988 and Erten and Razı 2009 for more). This evidence provides justification for the need to clarify the terminology applicable to academic integrity, which can serve as a common tool to exchange ideas among scholars from different disciplines. For instance, authorship is a key issue for academic scholars as it represents the basis for individual credit and reputation. Authorship criteria are, however, different across disciplines (see Tauginienè et al. 2018b). In a recent commentary, Kiser (2018) highlighted the importance of having common and stringent authorship criteria coupled to systems of ascertainment as a way to cope with authorshiprelated misconduct. This is a significant contemporary issue wherever careers are based on the number of authored papers. On the constructive side, fair authorship attribution fulfils some of the major requirements of science/scientists, i.e. giving proper credit to one's work and achievements. Indeed, not only does misattributing authorship provide undue advantage to individuals who did not contribute to a study, but this practice also undermines the value and credibility of appropriatelyassigned authorship in general. Abuse in attributing authorship can lead to unfair credit for scholarship in publications, which make an important contribution to the development of our collective knowledge and promotion of transdisciplinary collaboration. 
The journey undertaken by the whole team during the iterative co-creation process of putting together the glossary, refining the definitions, and constructing the taxonomy was a remarkable learning experience. The advantages to individuals contributors include knowledge improvement (e.g. different interpretations of terms, inter/transdisciplinary confrontation), collegial environment (e.g. sharing workloads, collaborative and positive attitude of whole team), community culture (e.g. possibility to discuss and reach consensus), task management (e.g. timely reminders with manageable deadlines). Most importantly authors have learnt about culture and language specific influences in interpreting the meanings of these terms. However, detailing individual experiences about this process is beyond the scope of this study. Yet we realized the necessity for everyone involved to question deeply their own understanding of the terms, their meaning, and different ways they can be used (e.g. connotation of a term 'compilation' varies by countries, i.e. in Lithuania, Slovakia it has a negative connotation while in the UK it has a positive connotation). The multicultural and interdisciplinary nature of the ENAI team forced all contributors to empathize and consider different viewpoints in order to reach agreement on concepts and terms.

The creation of these artefacts served to broaden the perspectives of all participants. Some contributors came to the activity with interest in research integrity and ethics, while others were primarily focused on integrity connected to student conduct and the educational process. However, the whole team gained a more holistic view of what academic integrity implies both for higher education and academic research. Also, the approach should be multi-faceted, we aimed to develop a taxonomy that would not only help academics (e.g. supervisors, teachers) and institutions (e.g. higher education institutions, offices of ombudspersons) but also could be widely used by the general public.

\section{Conclusions}

The outputs from this journey include the most comprehensive glossary available, compared with others identified, that takes into account several different educational and legal systems, various nuances based on national and cultural norms, and the varying requirements of several academic disciplines.

Previous studies on terminology generated a limited number of terms due to the restricted scope of their selected criteria for taxonomy development. To avoid this limitation, we investigated the entirety of the comprehensive glossary we had recently created, which allowed us to portray the breadth of academically honest and dishonest behaviors and to grasp specificities. However, we accept that rapidly evolving technologies and cultures drive to changes to academic malpractices and responses to such conduct, spawning new terms and changes in use of language; therefore, this taxonomy should be regularly revised and updated.

Having a clear content-specific definition for each term, and identifying with which of the three constituents it should be associated, helped us to facilitate its interpretation. This way we avoided making misleading judgements derived from cultural and institutional differences. This approach helped to make our taxonomy more comprehensive and explicit.

As ENAI consists of European interdisciplinary scholars from different countries and fields, it reflects the demographics of real-life academia; therefore, the terminology is expected to make a worthwhile and useful contribution to the field. Also, this freely-available taxonomy is able to serve as source material for teaching students, training scholars and raising the awareness of the general public. 
Funding Information Open access funding provided by Hanken School of Economics.

Open Access This article is distributed under the terms of the Creative Commons Attribution 4.0 International License (http://creativecommons.org/licenses/by/4.0/), which permits unrestricted use, distribution, and reproduction in any medium, provided you give appropriate credit to the original author(s) and the source, provide a link to the Creative Commons license, and indicate if changes were made.

\section{References}

Adam, L., Anderson, V., \& Spronken-Smith, R. (2017). 'It's not fair': Policy discourses and students' understandings of plagiarism in a New Zealand university. Higher Education, 74, 17-32.

Al-Marzouki, S., Roberts, I., Marshall, T., \& Evans, S. (2005). The effect of scientific misconduct on the results of clinical trials: A Delphi survey. Contemporary Clinical Trials, 26(3), 331-337.

Bamford, J., \& Sergiou, K. (2005). International students and plagiarism: An analysis of the reasons for plagiarism among international foundation students. Investigations in University Teaching and Learning, 2(2), 17-22.

Becher, T. (1989). Academic tribes and territories: Intellectual enquiry and the cultures of disciplines. Milton Keynes: The Society for Research into Higher Education.

Best Practices for Ensuring Scientific Integrity and Preventing Misconduct (2007). Organisation for Economic Co-Operation and Development Global Science Forum. http://www.oecd.org/science/inno/40188303.pdf. Accessed 15 May 2019.

Bohannon, J. (2013). Who's afraid of peer review? Science, 342(6154), 60-65.

Bretag, T. (2016). Defining academic integrity: International perspectives. In T. Bretag (Ed.), Handbook of academic integrity (pp. 3-180). Singapore: Springer.

Bretag, T., \& Mahmud, S. (2009). Self-plagiarism or appropriate textual re-use? Journal of Academic Ethics, 7 , 193-205.

Burrus, R. T., McGoldrick, K. M., \& Schuhmann, P. W. (2007). Self-reports of student cheating: Does a definition of cheating matter? Journal of Economic Education, 38(1), 3-16.

Carrell, P. L. (1988). Some causes of text-boundedness and schema interference in ESL reading. In P. L. Carrell, J. Devine, \& D. E. Eskey (Eds.), Interactive approaches to second language reading (pp. 101-113). New York: Cambridge University Press.

Caudron, S. (1994). Motivating creative employees calls for new strategies. The Personnel Journal, 73(5), 103106.

Cihan, N. (2014). Okullarda değerler eğitimi ve Türkiye'deki uygulamaya bir bakıș [Values education at schools and an overview on its implementation in Turkey]. Electronic Turkish Studies, 9(2), 429-236.

CSE White Paper on Promoting Integrity in Scientific Journal Publications (2012). Council of Science Editors editorial policy committee. http://www.councilscienceeditors.org/wp-content/uploads/entire_whitepaper.pdf. Accessed 15 May 2019.

Curran, W. J. (1976). Bioethics and health ethics: A critical examination of the new terminology. American Journal of Public Health, 66(5), 497-498.

de Weert, E. (2001). Pressures and prospects facing the academic profession in the Netherlands. Higher Education, 41, 77-101.

Declaration of Helsinki - Ethical Principles for Medical Research Involving Human Subjects (1964). World Medical Association. https://www.wma.net/policies-post/wma-declaration-of-helsinki-ethical-principles-formedical-research-involving-human-subjects/. Accessed 15 May 2019.

East, J. (2006). The problem of plagiarism in academic culture. International Journal for Educational Integrity, 2(2), 16-28.

East, J. (2010). Judging plagiarism: A problem of morality and convention. Higher Education, 59, 69-83.

Erten, İ. H., \& Razı, S. (2009). The effects of cultural familiarity on reading comprehension. Reading in a Foreign Language, 21(1), 60-77.

Fielden, K., \& Joyce, D. (2008). An analysis of published research on academic integrity. International Journal of Educational Integrity, 4(2), 4-24.

Foley, A. S., \& Davis, A. H. (2017). A guide to concept analysis. Clinical Nurse Specialist, 31(2), 70-73.

Gaižauskaite, I., \& Tauginiené, L. (2017). The maze of definitions on academic integrity and related terms - Is it easy to apply in practice? In EDULEARN17: 9th international conference on education and new learning technologies: Conference proceedings (pp. 7840-7844). Valensia: International Association of Technology, Education and Development (IATED). 
Garrett, G., \& Davies, G. (2010). Herding cats: Being advice to aspiring academic and research leaders. Axminster: Triarchy Press.

Geppert, M., \& Hollinshead, G. (2017). Signs of dystopia and democratization in global academia: Reflections on the precarious and destructive effects of the colonization of the Lebenswelt. Critical Perspectives on International Business, 13(2), 136-150.

Hall, J., \& Martin, B. R. (2019). Towards a taxonomy of research misconduct: The case of business school research. Research Policy, 48(2), 414-427.

Heitman, E., \& Litewka, S. (2011). International perspectives on plagiarism and considerations for teaching international trainees. Urologic Oncology, 29(1), 104-108.

Ho, K.-K. J. (2015). An exploration of the problem of plagiarism with the cognitive mapping technique. Systems Research and Behavioral Science, 32, 735-742.

Horbach, S. P. J. M., \& Halffman, W. (2017). Promoting virtue or punishing fraud: Mapping contrasts in the language of 'scientific integrity'. Science and Engineering Ethics, 23(6), 1461-1485.

Jordan, S. R. (2013). Conceptual clarification and the task of improving research on academic ethics. Journal of Academic Ethics, 11, 243-256.

Kiser, G. L. (2018). No more first authors, no more last authors. Nature, 561, 435.

Komić, D., Marušić, S. L., \& Marušić, A. (2015). Research integrity and research ethics in professional codes of ethics: Survey of terminology used by professional organizations across research disciplines. PLoS One, $10(7), \mathrm{e} 0133662$.

Krippendorff, K. (2013). Content analysis - An introduction to its methodology. Thousand Oaks: SAGE Publications.

Krippendorff, K., \& Bock, M. A. (2009). The content analysis reader. Los Angeles: SAGE Publications.

Kumar, M. N. (2008). A review of the types of scientific misconduct in biomedical research. Journal of Academic Ethics, 6, 211-228.

Liddicoat, A. J., Papademetre, L., Scarino, A., \& Kohler, M. (2003). Report on intercultural language learning. Canberra ACT: Commonwealth of Australia.

Macfarlane, B., Zhang, J., \& Pun, A. (2014). Academic integrity: A review of the literature. Studies in Higher Education, 39(2), 339-358.

Maddox, T. T. (2008). Chapter IX: Plagiarism and the community college. In T. S. Roberts (Ed.), Student plagiarism in an online world: Problems and solutions (pp. 124-143). Hershey: IGI Global.

Martin, B. R. (2013). Whither research integrity? Plagiarism, self-plagiarism and coercive citation in an age of research assessment. Research Policy, 42(5), 1005-1014.

McCabe, D. L., Trevino, L. K., \& Butterfield, K. D. (1999). Academic integrity in honor code and non-honor code environments. The Journal of Higher Education, 70(2), 211-234.

McClung, E. L., \& Schneider, J. K. (2015). A concept synthesis of academically dishonest behaviors. Journal of Academic Ethics, 13, 1-11.

Nuopponen, A. (2010a). Methods of concept analysis - A comparative study. LSP Journal, 1(1), 4-12.

Nuopponen, A. (2010b). Methods of concept analysis - Towards systematic concept analysis. LSP Journal, 1(2), $5-14$.

Nuopponen, A. (2011). Methods of concept analysis - Tools for systematic concept analysis. LSP Journal, 2(1), 4-15.

Park, C. (2003). In other (People's) words: Plagiarism by university students - Literature and lessons. Assessment \& Evaluation in Higher Education, 28(5), 471-488.

Picht, H. (2013). Concepts as reflection of societal changes. Terminologija, 20, 10-23.

Plašienková, Z. (2016). Etika a veda: poznámky k niektorým morálnym aspektom vedeckého výskumu [Ethics and Science: Remarks to Some Moral Aspects of Scientific Research]. In M. Szapuová, L. Bohunická, \& M. Chabada (Eds.), VEDA, RACIONALITA A HODNOTY [Science, Rationality and Values]: Conference proceedings (pp. 79-89). Bratislava: Stimul.

Regmi, K. (2011). Ethical and legal issues in publication and dissemination of scholarly knowledge: A summary of the published evidence. Journal of Academic Ethics, 9, 71-81.

Resnik, D. B., Neal, T., Raymond, A., \& Kissling, G. E. (2015a). Research misconduct definitions adopted by U.S. research institutions. Accountability in Research, 22, 14-21.

Resnik, D. B., Rasmussen, L. M., \& Kissling, G. E. (2015b). An international study of research misconduct policies. Accountability in Research, 22, 249-266.

Roberts, T. S. (Ed.). (2008). Student plagiarism in an online world: Problems and solutions. Hershey: IGI Global.

Salwén, H. (2015). The Swedish Research Council's definition of 'scientific misconduct': A critique. Science and Engineering Ethics, 21, 115-126.

Steneck, N. H. (2006). Fostering integrity in research: Definitions, current knowledge, and future directions. Science and Engineering Ethics, 12(1), 53-74. 
Szapuová, M., \& Nuhlíček, M. (2015). Veda a verejnost': Premeny spôsobov tvorby poznania a ich vzt'ahovania $\mathrm{k}$ verejnosti [science and the public: Changes in the methods of creating knowledge and relating them to the public]. In Z. Plašienková (Ed.), Bioetické výzvy a súčasnost' [bioethical challenges today] (pp. 249-260). Bratislava: Stimul.

Tauginiené, L. (2016). Embedding academic integrity in public universities. Journal of Academic Ethics, 14(4), 327-344.

Tauginienė, L., Gaižauskaite, I., Glendinning, I., Kravjar, J., Ojsteršek, M., Ribeiro, L., Odineca, T., Marino, F., Cosentino, M., Sivasubramaniam, S. (2018a). Glossary for academic integrity. ENAI Report 3G. http://www.academicintegrity.eu/wp/wp-content/uploads/2018/02/GLOSSARY_final.pdf. Accessed 15 May 2019.

Tauginienè, L., Ojsteršek, M., Foltýnek, T., Marino, F., Cosentino, M., Gaižauskaitė, I., Glendinning, I., Sivasubramaniam, S., Razi, S., Ribeiro, L., Odineca, T., Trevisiol, O. (2018b). General Guidelines for Academic Integrity. ENAI report 3A [online]. http://www.academicintegrity.eu/wp/wpcontent/uploads/2018/11/Guidelines_final.pdf. Accessed 15 May 2019.

Upleja, A. (2012). Akadēmiskais gadīgums un izpratne par to [academic honesty and its understanding]. $L B B$ Jauno speciālistu sekcija. https://lbbjss.wordpress.com/2012/04/27/akademiskais-godigums/. .

Weber-Wulff, D. (2014). False feathers: A perspective on academic plagiarism. Heidelberg, Berlin: Springer.

Weber-Wulff, D. (2016). Case study: Plagiarism in medical dissertations in Germany. Council of Europe, ETINED platform. https://rm.coe.int/090000168069226a. Accessed 15 May 2019.

Wells, F., \& Farthing, M. (2008). Fraud and misconduct in biomedical research. London: Royal Society of Medicine.

Publisher's Note Springer Nature remains neutral with regard to jurisdictional claims in published maps and institutional affiliations.

\section{Affiliations}

\section{Loreta Tauginienè $^{1} \cdot$ Inga Gaižauskaitè ${ }^{2} \cdot$ Salim Razi $^{3} \cdot$ Irene Glendinning $^{4} \cdot$ Shivadas Sivasubramaniam ${ }^{5}$. Franca Marino ${ }^{6}$ - Marco Cosentino ${ }^{6}$. Alla Anohina-Naumeca ${ }^{7}$. Julius $\operatorname{Kravjar}^{8}$}

1 Hanken School of Economics, Arkadiankatu 22, 00100 Helsinki, Finland

2 Lithuanian Social Research Centre, A. Goštauto g. 9, 01108 Vilnius, Lithuania

3 Canakkale Onsekiz Mart University, Barbaros Mahallesi, Belediyesi/Çanakkale Merkez/Çanakkale, 17100 Kepez, Turkey

4 Coventry University, Priory St, Coventry CV1 5FB, UK

5 University of Derby, Kedleston Rd, Derby DE22 1GB, UK

6 University of Insubria, Via Ottorino Rossi n. 9, 21100 Varese, Italy

7 Riga Technical University, Daugavgrivas street 25, Riga 1048, Latvia

8 Slovak Centre of Scientific and Technical Information, Lamačská cesta 8A, 81104 Bratislava, Slovakia 